\title{
Housing First and harm reduction: a rapid review and document analysis of the US and Canadian open-access literature
}

\author{
Dennis P. Watson ${ }^{1 *}$, Valery Shuman², James Kowalsky², Elizabeth Golembiewski ${ }^{3}$ and Molly Brown ${ }^{4}$
}

\begin{abstract}
Background: Housing First is an evidence-based practice intended to serve chronically homeless individuals with co-occurring serious mental illness and substance use disorders. Despite housing active substance users, harm reduction is an often-overlooked element during the Housing First implementation process in real-world settings. In this paper, we explore the representation of the Housing First model within the open-access scholarly literature as a potential contributing factor for this oversight.

Methods: We conducted a rapid review of the US and Canadian open-access Housing First literature. We followed a document analysis approach, to form an interpretation of the articles' content related to our primary research questions.

Results: A total of 55 articles on Housing First were included in the final analysis. Only 21 of these articles (38.1\%) included explicit mention of harm reduction. Of the 34 articles that did not discuss harm reduction, 22 provided a description of the Housing First model indicating it does not require abstinence from substance use; however, descriptions did not all clearly indicate abstinence was not required beyond program entry. Additional Housing First descriptions focused on the low-barrier entry criteria and/or the intervention's client-centeredness.

Conclusions: Our review demonstrated a lack of both explicit mention and informed discussion of harm reduction in the Housing First literature, which is likely contributing to the Housing First research-practice gap to some degree. Future Housing First literature should accurately explain the role of harm reduction when discussing it in the context of Housing First programming, and public agencies promoting Housing First uptake should provide resources for proper implementation and monitor program fidelity to prevent model drift.
\end{abstract}

Keywords: Harm reduction, Housing First, Rapid review, Document analysis, Housing, Substance use, Drug use, Implementation, Fidelity

\section{Background}

Developed in the 1990s [1], Housing First is an evidence-based practice that is the focal point of the US and Canadian governments' approaches to addressing homelessness today $[2,3]$. The model was developed to specifically serve chronically homeless individuals with co-occurring serious mental illness and substance use disorders. In contrast to more traditional housing approaches, Housing First does not require sobriety or

\footnotetext{
* Correspondence: dpwatson@iu.edu

${ }^{1}$ Department of Social and Behavioral Sciences, Indiana University Fairbanks

School of Public Health, 1050 Wishard Blvd, Indianapolis, IN 46202, USA

Full list of author information is available at the end of the article
}

treatment/service compliance as a condition for program entry or service continuation. As such, one of the key ingredients for a successful Housing First program is harm reduction-informed services [4-6]. In the context of the Housing First model, harm reduction is comprehensive and implemented with regard to substance use, management of psychiatric symptoms, and other areas of clients' lives that might make them vulnerable to harm [7]. Within a Housing First program, providers should actively and assertively engage clients in harm reduction strategies and utilize motivational interviewing techniques to guide them toward achieving their stated recovery goals [8]. Despite its status as an essential 
component of the intervention, harm reduction is often overlooked during the Housing First implementation process in real-world settings [5, 9, 10]. For instance, Watson et al. [5] found 18 of the 39 Housing First programs in their national sample were operating without harm reduction policies and procedures despite the presence of other key elements of program fidelity. In this paper, we explore the representation of the Housing First model within the open-access academic literature as one potential reason contributing to this oversight. Before focusing specifically on this issue, we provide an overview of some of the factors that have impeded the implementation of harm reduction in Housing First programs.

\section{Factors impeding harm reduction implementation}

Many problems related to the implementation of evidence-based practices can be traced to miscommunications or a lack of detailed explanation of interventions within the scientific literature $[11,12]$, and Housing First is no exception. Several misunderstandings of the Housing First model, including the essentialness of harm reduction, can be traced to the lack of fidelity guidelines at the time of its original diffusion across the USA in the early 2000s. Indeed, the US Department of Housing and Urban Development (HUD) commissioned a study more than 5 years after the initial push toward Housing First to begin to understand what fidelity to the model actually meant [13], and the first empirically based fidelity scales (which included harm reduction as a component) were not published until 2013 [5, 8]. Before fidelity guidelines were available, understandings of the model were formed as the result of a "telephone game" where housing providers obtained their information from documents produced by government and advocacy agencies with poor model descriptions that did not articulate elements of the harm reduction approach defined in later published fidelity scales $[14,15]$. This resulted in many US housing organizations implementing low-barrier entry requirements allowing active substance users (and other individuals engaged in various risky behaviors) without the harm reduction strategies necessary to keep them housed [5]. Demonstrating how this looks on the ground, though their work providing training and technical assistance, the first three authors of this paper regularly encounter Housing First case managers who are housing active substance users but do not use or cannot define what harm reduction is.

Another factor negatively impacting implementation of the Housing First model is resistance to harm reduction. Although it continues today, harm reduction was a much more politically charged topic in the USA before the Obama administration [16]. Indeed, in their 2007 HUD report, Pearson and colleagues [15] explain in a footnote that they chose to use the term "low-demand" in place of "harm reduction" due to the contentious nature of the term at the time their study was conducted. This choice in itself may have led to further misinterpretation of Housing First by service providers: in social service practice, "low-demand" is a term often applied to lowered service requirements, rather than an active approach to working with individuals who use substances. Additionally, commitment to abstinence-only approaches is common among people who work with substance users $[17,18]$, and this commitment is a noted barrier to the implementation of harm reduction in Housing First programs [10].

Finally, there has been a move toward a system-wide Housing First approach in the USA, which understands Housing First to be a general philosophy, rather than a specified program model [19]. A Housing First system places emphasis squarely on the low-barrier admission criteria, without as much attention paid to the ways to work with people once they are housed. As such, Housing First has become conflated with other low-barrier housing approaches, such as rapid re-housing. One of the key tools of this approach is a coordinated entry system that utilizes a community-wide and centralized intake to match individuals with low-barrier housing offering varying levels of support and financial services based on a combination of their particular needs, program eligibility criteria, and unit availability [20]. As researchers and practitioners working in the area of Housing First implementation, we have observed confusion on the part of housing providers who believe every program in their community is a Housing First program because they use coordinated entry. The former Deputy Director of the US Interagency Council on Homelessness has advocated for thinking of Housing First as a systems approach, arguing its framing as a program creates "a dynamic in which individual programs are pitted against one another" ([21], par. 7). However, this statement overlooks the fundamental fact that Housing First programming is evidence-based, while programs within a Housing First system operating using different program models are not.

The view of homelessness solutions in the USA is starting to change as more advocacy and government organizations are starting to place emphasis on harm reduction as a key component of the model (see [22]), which is likely owed to the development and publication of the fidelity guidelines previously discussed. However, based on our experience conducting a current Housing First implementation study [10] and additional work delivering Housing First technical assistance and training, significant barriers to the implementation of harm reduction still exist. In this paper, we are particularly interested in understanding the extent to which the openaccess scientific literature may be contributing to this issue. As such, we conducted a rapid review to 
understand how harm reduction was discussed within the available open-access Housing First literature in the USA and Canada.

Our reason for widening the focus beyond the USA is because Canada recently placed Housing First at the center of its housing strategy after demonstrated success of a multi-city randomized Housing First trial that followed strict fidelity criteria [2]. Furthermore, significant efforts to disseminate research among policymakers and service providers have been made in Canada. For example, the Canadian Observatory on Homelessness has developed the Homeless Hub [23], a comprehensive repository of homelessness and Housing First literature designed for dissemination among researchers, policymakers, and service providers. We chose to focus on open-access literature for several reasons. First, paywall barriers make it unlikely that non-open-access articles are heavily accessed by, and thus significantly influencing, the housing practice community, which primarily works for non-profit organizations with constrained resources (a fact well known by the second and third authors of this study who both work in this arena and regularly interact with those seeking Housing First resources as technical assistance and training providers). Second, websites, such as the Homeless Hub, may be "go-to" resources for service and training providers. However, even research dissemination sites such as this only provide open-access articles in full text due to journal subscription costs. Third, it has been hypothesized that because open-access articles are generally cited more rapidly and more often than non-open-access articles, knowledge translation to the broader community is also more likely for open-access research due to its accessibility $[24,25]$. Finally, it has been argued that the availability of open-access literature to practitioners is a critical component of evidence-based practice in community agencies [26]. Thus, the primary questions guiding this review were as follows: (1) To what degree does the open-access Housing First literature discuss harm reduction?; (2) How is harm reduction discussed in this literature?; and (3) How do articles that do not discuss harm reduction describe the Housing First model?

\section{Methods}

Rapid reviews are appropriate in cases where there is a need to develop a relatively comprehensive understanding of a well-defined issue within a short time frame and are generally conducted between 1 and 6 months [27-29]. To meet the deadline for the special issue of this journal, we conducted our review between December 3, 2016, and February 24, 2017. The stages in our review process included (1) problem formulation, (2) defining inclusion and exclusion criteria for the search, (3) identification and screening of the literature, and (4) data analysis. We have already outlined the formulation of the problem this study seeks to address in the last paragraph of the previous section.

\section{Defined parameters}

To be included in our review, articles had to (1) focus on housing programming for homeless individuals; (2) discuss a Housing First program or general Housing First practice in the USA or Canada (simply referencing Housing First was not enough to meet inclusion); (3) be empirical (e.g., quantitative, qualitative, or mixedmethod research, or a systematic review), non-empirical (e.g., theoretical, opinion-based and letter to the editor), or a study protocol (as protocols often have strong descriptions of interventions being tested); and (4) the article must be written in English.

\section{Literature identification and screening}

Our literature screening process comprised three steps (see Fig. 1). In step 1, we searched PubMed Central (PMC) and BioMed Central (BMC) for full-text articles containing the phrase "Housing First" anywhere within them. This search yielded 339 total articles (including duplicates), which were all pulled into Zotero bibliographic management software [30]. We then removed all duplicate articles and articles with titles clearly indicating they were not about Housing First programming, and we searched article abstracts when the title was not clear, which left us with 74 unique articles that were moved forward for more detailed screening.

In step 2, we searched the same databases for the phrases "supportive housing" and "supported housing" located anywhere within an article (our logic for this search being some programs that follow a Housing First approach might not have been described as such within their respective article). This search identified 871 total articles (including duplicates), which we pulled into Zotero. We applied the same title and abstract screening criteria as well as removing duplicates of articles found in step 1, which left 31 that were moved on for more detailed screening.

In step 3, we conducted more detailed screening of the 105 unique articles identified in the previous steps to locate and remove those not fitting inclusion criteria. We first imported all articles that made it past the first two steps into MAXQDA qualitative data analysis software [31]. Next, we focused specifically on the articles obtained in step 2 since, not having the words "Housing First" in them, they were most likely not to fit inclusion criteria. We identified and removed all step 2 articles that did not discuss programs targeting the homeless population, did not focus specifically on housing programming, and articles that discussed the homeless population in general. We did this by first using 


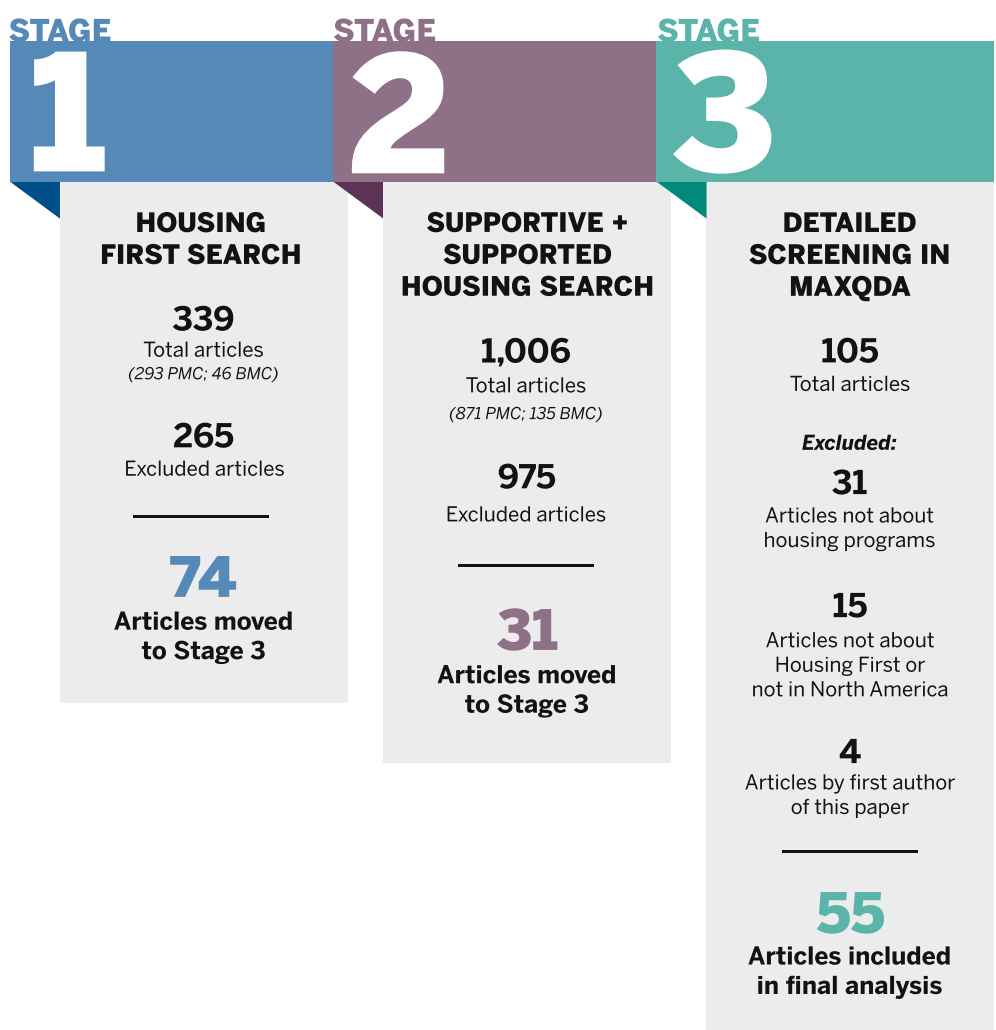

Fig. 1 Description of article identification and inclusion/exemption for all review stages

MAXQDA's query function to search articles not containing the string "homeless" anywhere within them and then reading the abstracts of all articles that did. At the end of this process, no unique articles identified in step 2 were demonstrated to meet our inclusion. We then thoroughly read all articles left to identify whether they were about Housing First programming in the USA or Canada and removed those that were not. We also removed all articles published by the authors of this paper, as their inclusion in the data would constitute circular logic since their work helped frame the problem that is the basis of this project. Step 3 screening resulted in a total of 55 articles that were moved to the analysis stage.

\section{Data analysis}

Unlike most systematic reviews, the goal of our analysis was not to evaluate the quality and results of identified literature or to integrate findings into coherent themes. Rather, we aimed to understand the representation of particular issues (e.g., descriptions of harm reduction and the Housing First model) regardless of a paper's results. As such, we conducted a document analysis, focusing on the articles' content related to the primary questions guiding the study to form interpretation of the textual data [32-34].
The first author carried out the analysis using MAXQDA. All articles were identified before any analysis began. As a first step, he categorized all 55 articles into one of the following two sets: (1) Housing First articles discussing harm reduction (HFwithHR) or (2) Housing First articles that did not discuss harm reduction (HFnoHR). To accomplish this, he first used the lexical search function in MAXQDA to identify all articles with the string "harm reduction" in them, placing them in the HFwithHR set, and moved all other articles into the HFnoHR set. Then he examined the placements of "harm reduction" in the articles and moved all articles where the string appeared only in the reference section to the HFnoHR set. Analysis of each document set diverged at this point due to the research questions.

As a first step in this analysis, the first author reviewed the articles and developed an initial coding scheme based on the content with separate sets of codes for each document set. For the HFwithHR set, codes were developed inductively by looking at the sections of the articles where Housing First was discussed and paying attention to how harm reduction was described in relation to the Housing First model. For the HFnoHR set, we were mainly interested in how they described the Housing First model without discussing harm reduction. We were particularly interested in whether the articles described 
sobriety requirements as being in opposition to the Housing First model and, if so, to what degree. Therefore, this set was coded deductively by creating three categories to sort the articles into based on how they explained the Housing First model: (1) Housing First not sufficiently explained, (2) Housing First described as not having sobriety requirements, and (3) Housing First described as being low-barrier, flexible, or emphasizing choice without explicitly discussing how sobriety requirements relate to the model. During analysis of the HFnoHR articles, the primary description of the Housing First model within the article was focused on, rather than isolated comments regarding it.

While all coding was conducted by the first author, we selected six articles (10\% of the sample) to be coded again by the fourth author to check for interrater agreement as a means of assessing the clarity of code definitions (the second coder was EG). We obtained 78\% agreement $(\mathrm{kappa}=0.74)$, indicating a moderate level of agreement, which is more than appropriate for an interpretive analysis [35].

\section{Results}

\section{Sample description}

Table 1 displays basic information regarding articles in the sample $(n=55)$. The years of publication ranged from 2004 to 2016 , and the year with the largest number of publications $(n=11)$ was 2013. Forty-eight publications were research articles, three were protocols, three were editorials or opinions, and one was a literature review. Thirty-seven were US articles and 18 were Canadian. Thirty-eight articles mentioned harm reduction somewhere in them, but only 21 mentioned it in the main text (i.e., parts of the article not including references or subtitles), resulting in $21 \mathrm{HFwithHR}$ articles and $34 \mathrm{HFnoHR}$ articles. Findings related to the analyses for each article set are presented separately below. Page numbers for quoted material reflect the location in the open-access versions of the articles.

\section{How harm reduction was discussed in articles mentioning harm reduction}

Of the 21 HFwithHR articles, the number of times harm reduction was mentioned in the main text ranged between 1 and 28 times with an average of $4.2(\mathrm{SD}=6.2)$ mentions. Only the article by Owczarzak et al. [36] did not discuss the relationship between harm reduction and Housing First in some way. Rather, they discussed it as a treatment approach used by some supportive housing programs.

Fifteen of the HFwithHR articles explicitly stated harm reduction was part of the Housing First model or used wording strongly suggesting the two approaches are part of a package deal; however, one only made this statement parenthetically [37]. Padgett [38] clearly discusses
Pathways to Housing as the original Housing First program that "departed from the 'treatment first' approach by offering [among a list of other components mentioned] harm reduction with respect to mental health treatment and substance abuse...." (p. 4-5). Stergiopoulos et al. [39] clearly demonstrate the connection between Housing First and harm reduction when they state "a harm reduction approach is followed" (p. 2) in Housing First programs. Though less strongly worded, Henwood et al. [40] discuss how Housing First "openly embraces harm reduction" (p. 2) and how harm reduction has been adopted as a "general framework" (p. 5) by the Housing First model.

Five articles discussed harm reduction as being compatible with Housing First practice or simply present in a program(s) without explicitly stating it was part of the model. The following statement by Collins et al. [41] provides an example of this: "Housing First is therefore consistent with harm reduction approaches, which deemphasize pathologizing alcohol use and support the realization of client-driven goals that can reduce harm and improve quality of life" (p. 2). In the case of an article by Somers et al. [42], the authors simply point out that "a harm reduction approach to substance use was promoted" (p. 3) in the program they studied. Similarly, Stergiopoulos et al. [43] state Housing First "service teams offered [intensive case management] using a recovery oriented, trauma informed approach and harm reduction principles" (p. 4) in the program they studied.

Ten articles actually described what harm reduction encompasses. Of these, only eight were also articles that had described harm reduction as a component of or consistent with the Housing First model. Seven articles described harm reduction only as it relates to substance use. These definitions ranged all the way from simply stating harm reduction was not concerned with abstinence from substance use [44] to more nuanced explanations such as Collins et al. [45] who state harm reduction uses:"...pragmatic strategies to minimize substance-related, negative consequences, while maintaining a nonjudgmental, empathetic stance and supporting the realization of clientdriven versus provider-driven goals" (p. 2). While not drawing the connection between harm reduction and Housing First, Owczarzak et al. [36] emphasized the various life areas-“social, legal, economic, and biological" (p. 3)-that harm reduction seeks to reduce the related negative consequences for. Pauly et al. [46] went beyond the individual client, discussing how harm reduction can focus on "safer settings (physical environments), organizational and governmental policies and practices that shift social, economic, and policy environments" (p. 3).

Only two articles used language suggesting harm reduction could focus on more than just substance use. In their results, Henwood et al. [40] used a quote from a Housing First provider demonstrating how harm reduction is about 
Table 1 Articles included in the literature review arranged by year of publication

\begin{tabular}{|c|c|c|c|c|c|}
\hline Author(s) & Year & Title & $\begin{array}{l}\text { Article } \\
\text { type }\end{array}$ & Country & $\begin{array}{l}\text { Harm reduction } \\
\text { mentioned }\end{array}$ \\
\hline $\begin{array}{l}\text { Tsemberis, Gulcur, and Nakae } \\
\text { [70] }\end{array}$ & 2004 & $\begin{array}{l}\text { Housing First, consumer choice, and harm reduction for } \\
\text { homeless individuals with a dual diagnosis }\end{array}$ & Research & USA & Yes \\
\hline $\begin{array}{l}\text { Milby, Schumacher, Wallace, } \\
\text { Freedman, and Vuchinich [71] }\end{array}$ & 2005 & $\begin{array}{l}\text { To house or not to house: the effects of providing housing } \\
\text { to homeless substance abusers in treatment }\end{array}$ & Research & USA & No \\
\hline $\begin{array}{l}\text { Dickson-Gomez, Convey, Hilario, } \\
\text { Corbett, and Weeks [72] }\end{array}$ & 2007 & $\begin{array}{l}\text { Unofficial policy: access to housing, housing information and } \\
\text { social services among homeless drug users in Hartford, Connecticut }\end{array}$ & Research & USA & No \\
\hline Kertesz et al. [59] & 2007 & $\begin{array}{l}\text { Long-term housing and work outcomes among treated } \\
\text { cocaine-dependent homeless persons }\end{array}$ & Research & USA & No \\
\hline Padgett [38] & 2007 & $\begin{array}{l}\text { There's no place like (a) home: ontological security among } \\
\text { persons with serious mental illness in the United States }\end{array}$ & Research & USA & Yes \\
\hline $\begin{array}{l}\text { Buchanan, Kee, Sadowski, } \\
\text { and Garcia [56] }\end{array}$ & 2009 & $\begin{array}{l}\text { The health impact of supportive housing for HIV-positive } \\
\text { homeless patients: a randomized controlled trial }\end{array}$ & Research & USA & No \\
\hline $\begin{array}{l}\text { Kertesz, Crouch, Milby, } \\
\text { Cusimano, and Schumacher [44] }\end{array}$ & 2009 & $\begin{array}{l}\text { Housing First for homeless persons with active addiction: } \\
\text { are we overreaching? }\end{array}$ & Research & USA & Yes \\
\hline Parker [58] & 2010 & $\begin{array}{l}\text { Housing as an intervention on hospital use: access among } \\
\text { chronically homeless persons with disabilities }\end{array}$ & Research & USA & No \\
\hline Tsai, Mares, and Rosenheck [57] & 2010 & $\begin{array}{l}\text { A multisite comparison of supported housing for chronically } \\
\text { homeless adults: "Housing First" versus "residential treatment first" }\end{array}$ & Research & USA & No \\
\hline Fitzpatrick-Lewis et al. [47] & 2011 & $\begin{array}{l}\text { Effectiveness of interventions to improve the health and housing } \\
\text { status of homeless people: a rapid systematic review }\end{array}$ & $\begin{array}{l}\text { Literature } \\
\text { review }\end{array}$ & USA & No \\
\hline Goering et al. [53] & 2011 & $\begin{array}{l}\text { The At Home/Chez Soi trial protocol: a pragmatic, multi-site, } \\
\text { randomised controlled trial of a Housing First intervention for } \\
\text { homeless individuals with mental illness in five Canadian cities }\end{array}$ & Protocol & Canada & No \\
\hline $\begin{array}{l}\text { Henwood, Stanhope, and } \\
\text { Padgett [50] }\end{array}$ & 2011 & $\begin{array}{l}\text { The role of housing: a comparison of front-line provider views in } \\
\text { housing first and traditional programs }\end{array}$ & Research & USA & No \\
\hline $\begin{array}{l}\text { Raven, Doran, Kostrowski, } \\
\text { Gillespie, and Elbel [73] }\end{array}$ & 2011 & $\begin{array}{l}\text { An intervention to improve care and reduce costs for high-risk } \\
\text { patients with frequent hospital admissions: a pilot study }\end{array}$ & Research & USA & Yes \\
\hline $\begin{array}{l}\text { Padgett, Stanhope, Henwood, } \\
\text { and Stefancic [74] }\end{array}$ & 2011 & $\begin{array}{l}\text { Substance use outcomes among homeless clients with serious } \\
\text { mental illness: comparing Housing First with treatment first } \\
\text { programs }\end{array}$ & Research & USA & Yes \\
\hline $\begin{array}{l}\text { Collins, Malone, Clifasefi, et al. } \\
\text { [75] }\end{array}$ & 2012 & $\begin{array}{l}\text { Project-based Housing First for chronically homeless individuals } \\
\text { with alcohol problems: within-subjects analyses of 2-year alcohol } \\
\text { trajectories }\end{array}$ & Research & USA & No \\
\hline $\begin{array}{l}\text { Hwang, Stergiopoulos, } \\
\text { O'Campo, and Gozdzik [76] }\end{array}$ & 2012 & $\begin{array}{l}\text { Ending homelessness among people with mental illness: the At } \\
\text { Home/Chez Soi randomized trial of a Housing First intervention in } \\
\text { Toronto }\end{array}$ & Research & Canada & Yes \\
\hline $\begin{array}{l}\text { Tsemberis, Kent, and Respress } \\
\text { [77] }\end{array}$ & 2012 & $\begin{array}{l}\text { Housing stability and recovery among chronically homeless persons } \\
\text { with co-occuring disorders in Washington, DC }\end{array}$ & Research & USA & Yes \\
\hline Stergiopoulos et al. [78] & 2012 & $\begin{array}{l}\text { Moving from rhetoric to reality: adapting Housing First for homeless } \\
\text { individuals with mental illness from ethno-racial groups }\end{array}$ & Research & Canada & Yes \\
\hline $\begin{array}{l}\text { Collins, Clifasefi, Andrasik, et al. } \\
\text { [45] }\end{array}$ & 2012 & $\begin{array}{l}\text { Exploring transitions within a project-based Housing First setting: } \\
\text { qualitative evaluation and practice implications }\end{array}$ & Research & USA & Yes \\
\hline Collins, Malone, and Larimer [41] & 2012 & $\begin{array}{l}\text { Motivation to change and treatment attendance as predictors } \\
\text { of alcohol-use outcomes among project-based Housing First } \\
\text { residents }\end{array}$ & Research & USA & Yes \\
\hline Collins, Clifasefi, Dana, et al. [63] & 2012 & $\begin{array}{l}\text { Where harm reduction meets housing first: exploring alcohol's } \\
\text { role in a project-based Housing First setting }\end{array}$ & Research & USA & Yes \\
\hline Collins, Malone, and Clifasefi [79] & 2013 & $\begin{array}{l}\text { Housing retention in single-site Housing First for chronically } \\
\text { homeless individuals with severe alcohol problems }\end{array}$ & Research & USA & No \\
\hline $\begin{array}{l}\text { Henwood, Shinn, Tsemberis, and } \\
\text { Padgett [40] }\end{array}$ & 2013 & $\begin{array}{l}\text { Examining provider perspectives within Housing First and } \\
\text { traditional programs }\end{array}$ & Research & USA & Yes \\
\hline Henwood, Stanhope, et al. [62] & 2013 & Addressing chronic disease within supportive housing programs & Research & USA & No \\
\hline O’Toole et al. [60] & 2013 & New to care: demands on a health system when homeless & Research & USA & No \\
\hline
\end{tabular}


Table 1 Articles included in the literature review arranged by year of publication (Continued)

\begin{tabular}{|c|c|c|c|c|c|}
\hline $\begin{array}{l}\text { Owczarzak, Dickson-Gomez, } \\
\text { Convey, and Weeks, [36] }\end{array}$ & 2013 & $\begin{array}{l}\text { What is "support" in supportive housing: client and service } \\
\text { providers' perspectives }\end{array}$ & Research & USA & Yes \\
\hline $\begin{array}{l}\text { Palepu, Patterson, } \\
\text { Moniruzzaman, Frankish, and } \\
\text { Somers [48] }\end{array}$ & 2013 & $\begin{array}{l}\text { Housing First improves residential stability in homeless adults } \\
\text { with concurrent substance dependence and mental disorders }\end{array}$ & Research & Canada & No \\
\hline $\begin{array}{l}\text { Patterson, Rezansoff, Currie, } \\
\text { and Somers [54] }\end{array}$ & 2013 & $\begin{array}{l}\text { Trajectories of recovery among homeless adults with mental } \\
\text { illness who participated in a randomised controlled trial of Housing } \\
\text { First: a longitudinal, narrative analysis }\end{array}$ & Research & Canada & No \\
\hline Somers, Patterson, et al. [61] & 2013 & $\begin{array}{l}\text { Vancouver At Home: pragmatic randomized trials investigating } \\
\text { Housing First for homeless and mentally ill adults }\end{array}$ & Research & Canada & No \\
\hline $\begin{array}{l}\text { Somers, Rezansoff, } \\
\text { Moniruzzaman, Palepu, and } \\
\text { Patterson [42] }\end{array}$ & 2013 & $\begin{array}{l}\text { Housing First reduces re-offending among formerly homeless } \\
\text { adults with mental disorders: results of a randomized controlled trial }\end{array}$ & Research & Canada & Yes \\
\hline Srebnik, Connor, and Sylla [80] & 2013 & $\begin{array}{l}\text { A pilot study of the impact of Housing First-supported housing for } \\
\text { intensive users of medical hospitalization and sobering services }\end{array}$ & Research & USA & Yes \\
\hline Stefancic et al. [37] & 2013 & Implementing Housing First in rural areas: Pathways Vermont & Research & USA & Yes \\
\hline Adair et al. [55] & 2014 & $\begin{array}{l}\text { Development and initial validation of the Observer-Rated Housing } \\
\text { Quality Scale (OHQS) in a multisite trial of Housing First }\end{array}$ & Research & Canada & No \\
\hline $\begin{array}{l}\text { Farquhar, Ryder, Henderlong, } \\
\text { Lowe, and Amann [81] }\end{array}$ & 2014 & $\begin{array}{l}\text { Listening to consumer perspectives to inform addictions and } \\
\text { housing-related practice and research }\end{array}$ & Research & USA & No \\
\hline Fleury, Grenier, and Vallée [82] & 2014 & $\begin{array}{l}\text { Evaluation of the implementation of the Montreal At Home/Chez } \\
\text { Soi project }\end{array}$ & Research & Canada & No \\
\hline Kertesz et al. [83] & 2014 & $\begin{array}{l}\text { Making Housing First happen: organizational leadership in VA's } \\
\text { expansion of permanent supportive housing }\end{array}$ & Research & USA & Yes \\
\hline $\begin{array}{l}\text { Kirst, Zerger, Harris, Plenert, and } \\
\text { Stergiopoulos [52] }\end{array}$ & 2014 & $\begin{array}{l}\text { The promise of recovery: narratives of hope among homeless } \\
\text { individuals with mental illness participating in a Housing First } \\
\text { randomised controlled trial in Toronto, Canada }\end{array}$ & Research & Canada & No \\
\hline $\begin{array}{l}\text { Mackelprang, Collins, and } \\
\text { Clifasefi [84] }\end{array}$ & 2014 & $\begin{array}{l}\text { Housing First is associated with reduced use of emergency } \\
\text { medical services }\end{array}$ & Research & USA & No \\
\hline Stergiopoulos et al. [39] & 2014 & Housing First: exploring participants' early support needs & Research & Canada & Yes \\
\hline $\begin{array}{l}\text { Aubry, Nelson, and Tsemberis } \\
\text { [85] }\end{array}$ & 2015 & $\begin{array}{l}\text { Housing First for people with severe mental illness who are } \\
\text { homeless: a review of the research and findings from the At } \\
\text { Home-Chez Soi demonstration project }\end{array}$ & Research & Canada & No \\
\hline Goering and Streiner [86] & 2015 & Putting housing first: the evidence and impact & $\begin{array}{l}\text { Editorial/ } \\
\text { opinion }\end{array}$ & Canada & No \\
\hline $\begin{array}{l}\text { Henwood, Byrne, and Scriber } \\
{[87]}\end{array}$ & 2015 & $\begin{array}{l}\text { Examining mortality among formerly homeless adults enrolled in } \\
\text { Housing First: an observational study }\end{array}$ & Research & USA & No \\
\hline Henwood, Stefancic, et al. [88] & 2015 & $\begin{array}{l}\text { Social relationships of dually diagnosed homeless adults following } \\
\text { enrollment in Housing First or traditional treatment services }\end{array}$ & Research & USA & No \\
\hline $\begin{array}{l}\text { Kertesz, Austin, Holmes, Pollio, } \\
\text { and Lukas [89] }\end{array}$ & 2015 & $\begin{array}{l}\text { Housing First and the risk of failure: a comment on Westermeyer } \\
\text { and Lee (2013) }\end{array}$ & $\begin{array}{l}\text { Editorial/ } \\
\text { opinion }\end{array}$ & USA & Yes \\
\hline Ly and Latimer [90] & 2015 & $\begin{array}{l}\text { Housing First impact on costs and associated cost offsets: a review } \\
\text { of the literature }\end{array}$ & Research & USA & No \\
\hline Smelson [91] & 2015 & $\begin{array}{l}\text { A cluster randomized Hybrid Type III trial testing an implementation } \\
\text { support strategy to facilitate the use of an evidence-based practice } \\
\text { in VA homeless programs }\end{array}$ & Protocol & USA & No \\
\hline Stergiopoulos et al. [43] & 2015 & $\begin{array}{l}\text { Effectiveness of Housing First with intensive case management in an } \\
\text { ethnically diverse sample of homeless adults with mental illness: a } \\
\text { randomized controlled trial }\end{array}$ & Research & Canada & Yes \\
\hline Woodhall-Melnik et al. [49] & 2015 & $\begin{array}{l}\text { The impact of a 24-month Housing First intervention on participants' } \\
\text { body mass index and waist circumference: Results from the At } \\
\text { Home/Chez Soi Toronto site randomized controlled trial }\end{array}$ & Research & Canada & No \\
\hline Brown et al. [92] & 2016 & $\begin{array}{l}\text { Pathways to homelessness among older homeless adults: results } \\
\text { from the HOPE HOME study }\end{array}$ & Research & USA & No \\
\hline Gabrielian et al. [93] & 2016 & Factors associated with premature exits from supported housing & Research & USA & No \\
\hline
\end{tabular}


Table 1 Articles included in the literature review arranged by year of publication (Continued)

\begin{tabular}{|c|c|c|c|c|c|}
\hline Kennedy et al. [94] & 2016 & $\begin{array}{l}\text { A computer-assisted motivational social network intervention to } \\
\text { reduce alcohol, drug and HIV risk behaviors among Housing First } \\
\text { residents }\end{array}$ & Protocol & USA & No \\
\hline Killaspy [95] & 2016 & Supported accommodation for people with mental health problems & $\begin{array}{l}\text { Editorial/ } \\
\text { opinion }\end{array}$ & USA & No \\
\hline O'Campo et al. [96] & 2016 & $\begin{array}{l}\text { How did a Housing First intervention improve health and social } \\
\text { outcomes among homeless adults with mental illness in Toronto? } \\
\text { Two-year outcomes from a randomised trial }\end{array}$ & Research & Canada & No \\
\hline Stergiopoulos et al. [97] & 2016 & $\begin{array}{l}\text { The effectiveness of a Housing First adaptation for ethnic minority } \\
\text { groups: findings of a pragmatic randomized controlled trial }\end{array}$ & Research & Canada & No \\
\hline Pauly et al. [46] & 2016 & $\begin{array}{l}\text { Finding safety: a pilot study of managed alcohol program participants' } \\
\text { perceptions of housing and quality of life }\end{array}$ & Research & Canada & Yes \\
\hline
\end{tabular}

more than just substance use in that "It extends not just with drug use. It expands with working and a whole slew of things, relationships, and you can apply it to almost every service you provide" (p. 5). Somers et al. [42] stated that harm reduction was applied generally by staff toward risky behaviors; however, they parenthetically offer nonabstinence-based substance use treatment as their only example.

Of the ten articles that described harm reduction, five also contrasted it directly with traditional continuum of care or abstinence-only approaches to housing service provision. For example, Collins et al. [45] stated:

One of the fundamental theoretical differences between the continuum/medical and Housing First/harm reduction models lies in the understanding of the mechanism by which individuals are likely to change their behavior. The continuum/medical model holds that alcohol behavior change...is optimally achieved through...treatment attendance and rewarding more "desirable" behavior...In contrast, the Housing First/harm reduction model is built on the assertion that behavior change is most lasting if it is client-driven....(p. 2)

The above selection from Collins et al. was the most detailed example, as the other articles simply pointed to the models as "different" or contrasted how they approach substance use without delving into the specific logics underlying them. However, Pauly et al. [46] provided a unique contrast in that they pointed to the controversial nature of harm reduction because it was aimed "to reduce the harms of substance use rather than promote abstinence or reduce substance use" (p. 9), where other articles simply stated the continuum of care/abstinence-only approach was more ubiquitous.

\section{Discussions of Housing First in articles not mentioning harm reduction}

Of the 34 HFnoHR articles, only one, a literature review of various housing interventions by Fitzpatrick [47], did not provide any description of the Housing First model. Twenty-two of these articles described Housing First in a manner indicating it "does not require abstinence from drugs and alcohol among clients" [48] (p. e34). The following selection from Woodhall-Melnik et al. [49] offers one of the strongest descriptions of the way Housing First programs approach substance use, which would be consistent with a harm reduction approach:

Housing First involves providing low-barrier, rapid access to housing and mental health support services wherein individuals are given access to independent housing with no sobriety or mental health treatment enrollment or compliance requirements. (p. 2)

The strength of this description lies in its discussion of both criteria for program eligibility and continuance of housing as not requiring abstinence. Articles by Henwood et al. [50] and Fleury et al. [51] provided similarly strong examples.

In contrast to this, 13 articles only stated sobriety was not an eligibility requirement for housing access without discussing how Housing First programs dealt with substance use after clients were housed. For instance, Kirst et al. [52] state:

Housing First is an intervention for individuals experiencing homelessness and mental illness which places individuals into permanent independent Housing First-without prerequisites for sobriety and treatment-and offers flexible access to supportive health services. (p. 2)

"Immediate provision/access" was a common phrase used in conjunction with descriptions of Housing First's lack of sobriety requirements for intake [37, 53-55].

Finally, there were four examples where the relationship between Housing First and substance use was not clearly stated or was convoluted. In three of these examples, Housing First's rules around sobriety were described in 
contrast to traditional, abstinence-focused programming. Buchanan et al. [56] indicated:

Housing First is a theory that homeless individuals are best stabilized through housing regardless of the personal challenges they may experience. This contrasts with the traditional housing readiness system that preferentially houses more stable and organized individuals by requiring repeated follow-up visits, stable contact information, and often sobriety.... (p. S679)

In the article by Tsai et al. [57], the authors make the following statement that could be interpreted in a manner contrasting the Housing First model:

The Housing First program, as its name suggests, offers homeless clients immediate independent housing off the streets and attempts to find housing that satisfies their needs and preferences with only limited requirements for psychiatric treatment or sobriety. (p. 2)

The authors' statement that Housing First offers "limited requirements...for sobriety" could be construed by some to mean sobriety requirements are compatible with the model on some level.

Ten articles did not discuss substance use as it relates to the Housing First model. And seven of these ten discussed Housing First as being "low-barrier" or providing "immediate access" to clients coming directly off the street, while also highlighting the importance of supportive services: "The Housing First methodology is a reversal of common practice in the United States by providing more immediate housing prior to supportive services." ([58] p. 913). The articles by Kertesz et al. [59] and O'Toole et al. [60] simply mention the Housing First as being low-demand, meaning they did not require participation in any specific services.

Finally, five of the ten articles that did not directly discuss how Housing First approaches substance use, including three that had also discussed the model as "low-barrier," described Housing First in terms of its client-centeredness. For instance, Somers et al. [61] focused primarily on the choice the model gives to clients regarding housing location:

Housing First emphasizes the value of client choice... Housing First involves building a portfolio of rental accommodations (typically apartments) scattered throughout different neighborhoods, thereby providing clients with meaningful choices concerning the location and setting of the residence. (p. 2)

Providing another example, Henwood at al. [62] discussed this issue more in terms of the tailoring of supportive services to the individual client:
[Housing First] programs provide immediate access to publicly subsidized housing rented from private landlords along with flexible supports designed specifically for individuals...the intensity of services is based on individual need. (p. 2)

\section{Discussion}

Our findings demonstrate there is considerable variation in the extent to which harm reduction is described within a sample of US and Canadian open-access Housing First literature. And, while we cannot state there is a direct correlation between weak intervention portrayals and problems with Housing First implementation, our analysis does demonstrate that the inconsistent use of harm reduction demonstrated to exist in practice $[5,9,10]$ is mirrored by inconsistent descriptions in the literature.

The majority of the articles in our sample did not discuss harm reduction within their main text, and there was significant variation among those that did regarding how harm reduction was discussed. While the majority of the HFwithHR articles explicitly identified harm reduction as part of Housing First, language discussing harm reduction as compatible with, rather than critical to, Housing First could be taken to mean harm reduction is an optional component of the intervention. More than half the HFwithHR articles did not clearly define harm reduction or how it is applied in Housing First programming. Finally, few HFwithHR described specific engagement strategies, such as motivational interviewing, that were used within the model to promote harm reduction. Therefore, housing providers may come away with a narrow view of the harm reduction approach as it is implemented in Housing First.

The emphasis placed on harm reduction practices appeared to be particularly common in articles focusing on populations with primary substance use disorders. For example, the HFwithHR article by Pauly and colleagues [46] and three HFwithHR articles by Collins and colleagues $[41,45,63]$ described Housing First programs designed specifically for individuals with severe alcohol problems. A lack of emphasis on harm reduction in the broader Housing First literature runs the risk of conveying it is not a key element of the intervention unless substance use is the primary program focus. Further, it is possible housing providers, viewing specialty programs as unrelated to the services they provide, might not extend harm reduction approaches to their programs.

The fact that 18 of the HFnoHR articles referenced literature with "harm reduction" in their titles and HFnoHR authors also had articles appearing in the HFwithHR set indicates there is likely an awareness of the importance of harm reduction that is not evidenced in the main text of many publications. One likely reason for this is lack of significant space to include rich 
descriptive information due to scholarly journal page limitations [64]. One positive note is that the majority of the HFnoHR articles at least stated the model does not require abstinence of residents; however, many of these relayed information in such a way as to suggest abstinence was not a requirement of entry without clearly stating clients should not lose their housing due to substance use. Lack of clarity regarding this issue could account for why some programs feel as though they can require abstinence after program entry.

We realize guidance regarding program implementation is not the goal of most scholarly articles, and we do not expect researchers will begin providing detailed guidance on Housing First implementation any time soon. However, our findings do stress the importance for researchers to more accurately convey the role of harm reduction and the ways it is utilized when it is described in Housing First research and to consider moving beyond journal publication as a singular form of dissemination to help clear up misconceptions, improve fidelity of implementation, and close the research-practice gap $[65,66]$. When doing this, we suggest authors focus on the definition of harm reduction provided in existing fidelity measures, which are highly compatible: "Participants are not required to abstain from alcohol and/or drugs and staff work consistently with participants to reduce the negative consequences of use..." ([67], p. 247); "Reduce the negative consequences related to substance abuse (and other high-risk behaviors) rather than eliminating substance use altogether" ([5], p. 16). In addition, drawing on texts with more comprehensive descriptions of the Housing First model (e.g., [7]) may provide a broader view of harm reduction elements in Housing First, such as its applicability to psychiatric symptoms and other harmful behaviors.

It is possible that the research-practice gap will widen in the USA due to the current move to a housing systems approach informed by a Housing First philosophy $[19,21]$. This is because more programs existing within coordinated entry systems are likely to call themselves "Housing First" when they have not appropriately implemented the model. This could also lead to more negative perceptions of Housing First as programs that believe they are working within its parameters obtain negative service outcomes [68]. Perhaps a better term for these systems would be "low-barrier" or "coordinated entry" systems to avoid likely confusion. Another approach might be to require programs to demonstrate fidelity to the model if they wish to receive federal funding. While these issues are largely set within the US context, the lack of explicit discussion of harm reduction in more than $50 \%$ of the Canadian articles might foreshadow a drift in Housing First fidelity [69] as the model begins to disseminate in light of new government policies.
This project faces limitations common to any rapid review, namely we had to make precise decisions regarding our research questions and boundaries of the literature we focused on due to time constraints. While a look at the broader Housing First literature may have yielded a sample with richer data, focusing on the scholarly literature most available to policymakers and practitioners was the best for understanding how it may be contributing to the Housing First research-practice gap. Our findings did demonstrate that a broader systematic review of the Housing First literature, including the gray literature, would be a worthwhile endeavor to produce a stronger understanding of the representation of harm reduction within it, as well as how these messages are being interpreted and disseminated by government and professional organizations. To better understand issues affecting the translation of the Housing First model, future work could seek to better identify the extent to which the scientific literature and other possible factors (e.g., other pathways of information diffusion, culture, funding, politics) might be contributing to misinterpretations of the model through such methods as key stakeholder interviews or a survey of Housing First practitioners. This work would benefit work related to Housing First specifically, as well as the broader literature on program implementation.

\section{Conclusions}

The findings of this review demonstrate a lack of both explicit mention and informed discussion of harm reduction in the scholarly open-access Housing First literature from the USA and Canada, which confirms assumptions based on previous literature and our experiences as Housing First researchers and professionals assisting with Housing First training and technical assistance. Future authors of scholarly literature should be weary to accurately explain the role of harm reduction when it is discussed in the context of Housing First programming. They should also explicitly refer readers to fidelity guidelines to avoid future problems with the implementation of harm reduction in real-world programs. Additionally, public and government agencies wishing to promote the evidence-based Housing First model should include guidance regarding essential program elements based on established fidelity guidelines, provide linkage to resources for programs and practitioners to build the necessary skills for success, and consider requiring fidelity assessments for programs labeling themselves "Housing First" in order to prevent excessive model drift.

\section{Abbreviations}

HFnoHR: Articles in our sample without the string "harm reduction" in the main body of the text; HFwithHR: Articles in our sample with the string "harm reduction" in the main body of the text; HUD: US Department of Housing and Urban Development 


\section{Acknowledgements}

We would like to thank Emily Abrams, Design Intern, for developing Fig. 1, and John Coberg, Undergraduate Research Assistant, for his assistance with data cleaning and organization.

\section{Funding}

This project is supported by the National Alliance on Drug Abuse (NIDA) R34DA036001.

\section{Availability of data and materials}

Data analyzed in this article are publicly available through the BioMed Central and PubMed Central databases. A list of all articles screened in this review is available from the first author upon request.

\section{Authors' contributions}

DPW developed the research questions with assistance from VS and JK, led the review and analysis, and wrote the manuscript draft. VS developed the initial idea for the paper and, together with JK, assisted DPW with the development of research questions, and they contributed expert knowledge as practitioners to the development of the introduction and discussion sections. EG assisted with data analysis and critically reviewed the manuscript for intellectual content. MB critically reviewed the manuscript for intellectual content and provided her expertise as a Housing First researcher to the development of the literature review and discussion sections. All authors read and approved the final manuscript.

\section{Competing interests}

The authors declare that they have no competing interests.

\section{Ethics approval and consent to participate}

Ethics approval was not required for this study, as no human subject data were collected or used.

\section{Publisher's Note}

Springer Nature remains neutral with regard to jurisdictional claims in published maps and institutional affiliations.

\section{Author details}

'Department of Social and Behavioral Sciences, Indiana University Fairbanks School of Public Health, 1050 Wishard Blvd, Indianapolis, IN 46202, USA. ${ }^{2}$ Heartland Health Outreach, Midwest Harm Reduction Institute, 1207 W. Leland Ave., Chicago, IL 60640, USA. ${ }^{3}$ Department of Health Policy and Management, Indiana University Fairbanks School of Public Health, 1050 Wishard Blvd, Indianapolis, IN 46202, USA. ${ }^{4}$ Department of Psychology, DePaul University, 2219 N. Kenmore Ave., Chicago, IL 60614, USA.

Received: 28 February 2017 Accepted: 16 May 2017

Published online: 23 May 2017

\section{References}

1. Tsemberis S, Asmussen S. From streets to homes - the Pathways to Housing Consumer Preference Supported Housing Model. Alcohol Treat Q. 1999;17:113-31.

2. Gaetz S, Scott F, Gulliver T. Housing First in Canada: supporting communities to end homelessness. Canada Homelessness Research Network; 2013. https:// yorkspace.library.yorku.ca/xmlui/handle/10315/29317. Accessed 22 Feb 2017.

3. Homelessness USIC on. Opening doors: federal strategic plan to prevent and end homelessness. US Interagency Council on Homelessness; 2010.

4. U.S. Substance Abuse and Mental Health Services Administration (SAMHSA). National Registry of Evidence-Based Programs and Practices. 2015. http:// www.samhsa.gov/nrepp. Accessed 5 Feb 2017.

5. Watson DP, Orwat J, Wagner DE, Shuman V, Tolliver R. The Housing First model (HFM) fidelity index: designing and testing a tool for measuring integrity of housing programs that serve active substance users. Subst Abuse Treat Prev Policy. 2013;8:16.

6. Watson DP, Wagner DE, Rivers M. Understanding the critical ingredients for facilitating consumer change in Housing First programming: a case study approach. J Behav Health Serv Res. 2013;40:169-79.

7. Tsemberis S. Housing First: the Pathways Model to End Homelessness for people with mental illness and addiction. Center City: Hazelden; 2010.

8. Henwood, BF, Tiderington, E. Frontline practice in housing first programs. In: Housing, citizenship, and communities for people with serious mental illneess: theory, research, practice, and policy perspectives, New York: Oxford University Press, 2017. p. 338-350.

9. George C, Nargang Chernega J, Stawiski S, Figert A, Valdivia Bendixen A. Connecting fractured lives to a fragmented system: Chicago housing for health partnership. Equal Oppor Int. 2008;27:161-80.

10. Watson DP, Young J, Ahonen E, Xu H, Henderson M, Shuman V, et al. Development and testing of an implementation strategy for a complex housing intervention: protocol for a mixed methods study. Implement Sci. 2014;9:138.

11. Durlak JA, DuPre EP. Implementation matters: a review of research on the influence of implementation on program outcomes and the factors affecting implementation. Am J Community Psychol. 2008;41:327-50.

12. Colditz GA. The promise and challenges of dissemination and implementation research. In: Brownson RC, Colditz GA, Proctor EK, editors. Dissemination and implementation research in health: translating science into practice. New York: Oxford University Press, Inc.; 2012. p. 3-22.

13. Pearson $\mathrm{CL}$, Montgomery AE, Locke $\mathrm{G}$. Housing stability among homeless individuals with serious mental illness participating in housing first programs. J Community Psychol. 2009;37:404-17.

14. National Alliance to End Homelessness. A plan, not a dream: how to end homelessness in ten years. Washington DC: Natl Alliance End Homelessness; 2000.

15. Pearson CL, Locke G, McDonald WR. The applicability of Housing First models to homeless persons with serious mental illness: final report. Washington DC: US Department of Housing and Urban Development, Office of Policy Development and Research; 2007.

16. Grund J-PC. Harm reduction in the United States at a moment of change: moving innovation from grassroots to mainstream? Addiction. 2009;104:1450-2.

17. Davis D, Hawk M. Incongruence between trauma center social workers' beliefs about substance use interventions and intentions to intervene. Soc Work Health Care. 2015;54:320-44.

18. Rosenberg H, Phillips KT. Acceptability and availability of harm-reduction interventions for drug abuse in American substance abuse treatment agencies. Psychol Addict Behav. 2003;17:203.

19. Schiff JW, Schiff RAL. Housing First: paradigm or program? J Soc Distress Homeless. 2014:23:80-104.

20. U.S. Department of Housing and Urban Development. Coordinated entry policy brief. https://www.hudexchange.info/resource/4427/coordinatedentry-policy-brief/. Accessed 22 Feb 2017.

21. Cho R. Four clarifications about Housing First. 2014. https://www.usich.gov/ news/four-clarifications-about-housing-first. Accessed 22 Feb 2017.

22. U. S. Interagency Council on Homelessness. Housing First checklist: assessing projects and systems for a Housing First orientation. 2016. https://www.usich. gov/tools-for-action/housing-first-checklist. Accessed 22 Feb 2017.

23. The Homeless Hub. http://homelesshub.ca/. Accessed 6 May 2017.

24. Eysenbach G. Citation advantage of open access articles. PLoS Biol. 2006;4:e157.

25. Norris M, Oppenheim C, Rowland F. The citation advantage of open-access articles. J Am Soc Inf Sci Technol. 2008;59:1963-72.

26. Bowen EA, Mattaini MA, De Groote SL. Open access for social work research and practice. J Soc Soc Work Res. 2013:4:31-46.

27. Booth A, Sutton A, Papaioannou D. Systematic approaches to a successful literature review. Los Angeles: Sage; 2016.

28. Harker J, Kleijnen J. What is a rapid review? A methodological exploration of rapid reviews in health technology assessments. Int J Evid Based Healthc. 2012;10:397-410.

29. Schünemann HJ, Moja L. Reviews: rapid! rapid! rapid! ... and systematic. Syst Rev. 2015;4:4.

30. Roy Rosenzweig Center for History and New Media. Zotero https://www. zotero.org/. Accessed 24 Feb 2017.

31. MAXQDA, software for qualitative data analysis. VERBI Software - Consult Sozialforschung GmbH. Berlin, Germany. 1989-2016. http://www.maxqda. com/faq/how-do-i-cite-maxqda.

32. Bowen GA. Document analysis as a qualitative research method. Qual Res J. 2009;9:27-40

33. Hsieh H-F, Shannon SE. Three approaches to qualitative content analysis. Qual Health Res. 2005;15:1277-88.

34. Kuckartz U. Qualitative text analysis: a guide to methods, practice and using software. Los Angeles: Sage; 2014.

35. McHugh ML. Interrater reliability: the kappa statistic. Biochem Medica. 2012; 22:276-82.

36. Owczarzak J, Dickson-Gomez J, Convey M, Weeks M. What is "support" in supportive housing: Client and service providers' perspectives. Hum Organ. 2013;72:254-62. 
37. Stefancic A, Henwood BF, Melton H, Shin S-M, Lawrence-Gomez R, Tsemberis S. Implementing Housing First in rural areas: pathways Vermont. Am J Public Health. 2013;103:S206-9.

38. Padgett DK. There's no place like (a) home: ontological security among persons with serious mental illness in the United States. Soc Sci Med. 2007:64:1925-36

39. Stergiopoulos V, Gozdzik A, O'Campo P, Holtby AR, Jeyaratnam J, Tsemberis S. Housing First: exploring participants' early support needs. BMC Health Serv Res. 2014;14:167.

40. Henwood BF, Shinn M, Tsemberis S, Padgett DK. Examining provider perspectives within Housing First and traditional programs. Am J Psychiatr Rehabil. 2013;16:262-74.

41. Collins SE, Malone DK, Larimer ME. Motivation to change and treatment attendance as predictors of alcohol-use outcomes among project-based Housing First residents. Addict Behav. 2012;37:931-9.

42. Somers JM, Rezansoff SN, Moniruzzaman A, Palepu A, Patterson M. Housing First reduces re-offending among formerly homeless adults with mental disorders: results of a randomized controlled trial. PLoS One. 2013;8:e72946.

43. Stergiopoulos V, Gozdzik A, Misir V, Skosireva A, Connelly J, Sarang A, et al. Effectiveness of Housing First with intensive case management in an ethnically diverse sample of homeless adults with mental illness: a randomized controlled trial. PLoS One. 2015;10:e0130281.

44. Kertesz SG, Crouch K, Milby JB, Cusimano RE, Schumacher JE. Housing First for homeless persons with active addiction: are we overreaching? Milbank Q. 2009;87:495-534.

45. Collins SE, Clifasefi SL, Andrasik MP, Dana EA, Stahl N, Kirouac M, et al. Exploring transitions within a project-based Housing First setting: qualitative evaluation and practice implications. J Health Care Poor Underserved. 2012;23:1678.

46 Pauly BB, Gray E, Perkin K, Chow C, Vallance K, Krysowaty B, et al. Finding safety: a pilot study of managed alcohol program participants' perceptions of housing and quality of life. Harm Reduct J. 2016;13:15.

47 Fitzpatrick-Lewis D, Ganann R, Krishnaratne S, Ciliska D, Kouyoumdjian F, Hwang SW. Effectiveness of interventions to improve the health and housing status of homeless people: a rapid systematic review. BMC Public Health. 2011;11:638.

48 Palepu A, Patterson ML, Moniruzzaman A, Frankish CJ, Somers J. Housing First improves residential stability in homeless adults with concurrent substance dependence and mental disorders. Am J Public Health. 2013;103:e30-6.

49 Woodhall-Melnik J, Misir V, Kaufman-Shriqui V, O'Campo P, Stergiopoulos V, Hwang S. The impact of a 24 month Housing First intervention on participants' body mass index and waist circumference: results from the At Home / Chez Soi Toronto site randomized controlled trial. PLoS One. 2015;10:e0137069.

50 Henwood BF, Stanhope V, Padgett DK. The role of housing: a comparison of front-line provider views in Housing First and traditional programs. Adm Policy Ment Health Ment Health Serv Res. 2011;38:77-85.

51 Fleury MJ, Mercier C, Denis J-L. Regional planning implementation and its impact on integration of a mental health care network. Int J Health Plann Manage. 2002;17:315-32

52 Kirst M, Zerger S, Harris DW, Plenert E, Stergiopoulos V. The promise of recovery: narratives of hope among homeless individuals with mental illness participating in a Housing First randomised controlled trial in Toronto Canada. BMJ Open. 2014;4:e004379.

53 Goering PN, Streiner DL, Adair C, Aubry T, Barker J, Distasio J, et al. The At Home/Chez Soi trial protocol: a pragmatic, multi-site, randomised controlled trial of a Housing First intervention for homeless individuals with mental illness in five Canadian cities. BMJ Open. 2011;1:e000323.

54 Patterson ML, Rezansoff S, Currie L, Somers JM. Trajectories of recovery among homeless adults with mental illness who participated in a randomised controlled trial of Housing First: a longitudinal, narrative analysis. BMJ Open. 2013;3:e003442.

55 Adair CE, Kopp B, Lavoie J, Distasio J, Hwang SW, Watson A, et al. Development and initial validation of the Observer-Rated Housing Quality Scale (OHQS) in a multisite trial of Housing First. J Urban Health Bull N Y Acad Med. 2014;91:242-55

56 Buchanan D, Kee R, Sadowski LS, Garcia D. The health impact of supportive housing for HIV-positive homeless patients: a randomized controlled trial. Am J Public Health. 2009;99 Suppl 3:S675-80.

57 Tsai J, Mares AS, Rosenheck RA. A multisite comparison of supported housing for chronically homeless adults: "housing first" versus "residential treatment first". Psychol Serv. 2010;7:219.
58 Parker D. Housing as an intervention on hospital use: access among chronically homeless persons with disabilities. J Urban Health. 2010;87:912-9.

59 Kertesz SG, Mullins AN, Schumacher JE, Wallace D, Kirk K, Milby JB. Longterm housing and work outcomes among treated cocaine-dependent homeless persons. J Behav Health Serv Res. 2007;34:17-33.

60 O'Toole TP, Bourgault C, Johnson EE, Redihan SG, Borgia M, Aiello R, et al. New to care: demands on a health system when homeless veterans are enrolled in a medical home model. Am J Public Health. 2013;103:S374-9.

61 Somers JM, Patterson ML, Moniruzzaman A, Currie L, Rezansoff SN, Palepu A, et al. Vancouver At Home: pragmatic randomized trials investigating Housing First for homeless and mentally ill adults. Trials. 2013;14:365.

62 Henwood BF, Stanhope V, Brawer R, Weinstein LC, Lawson J, Stwords E, et al. Addressing chronic disease within supportive housing programs. Prog Community Health Partnersh Res Educ Action. 2013;7:67.

63 Collins SE, Clifasefi SL, Dana EA, Andrasik MP, Stahl N, Kirouac M, et al. Where harm reduction meets Housing First: exploring alcohol's role in a project-based housing first setting. Int J Drug Policy. 2012;23:111-9.

64 Weiner BJ, Amick HR, Lund JL, Lee S-YD, Hoff TJ. Review: use of qualitative methods in published health services and management research: a 10-year review. Med Care Res Rev. 2011;68:3-33.

65 Institute of Medicine (US) Commitee on Quality of Healthcare in America. Crossing the quality chasm: a new health system for the 21st century. Washington: The National Academies Press; 2001.

66 Kerner J, Rimer B, Emmons K. Introduction to the special section on dissemination: dissemination research and research dissemination: how can we close the gap? Health Psychol. 2005;24:443-6.

67 Stefancic A, Tsemberis S, Messeri P, Drake R, Goering P. The Pathways Housing First Fidelity Scale for individuals with psychiatric disabilities. Am J Psychiatr Rehabil. 2013;16:240-61.

68 Scanlon JW, Horst H, Nay JN, Schmidt RE, Waller AE. Evaluability assessment: avoiding type III and IV errors. In: Evaluation Management: A Source Book for Readings. Charlottesville: U. S. Civil Service Commission; 1997. p. 71-90.

69 Aarons GA, Green AE, Palinkas LA, Self-Brown S, Whitaker DJ, Lutzker JR, et al. Dynamic adaptation process to implement an evidence-based child maltreatment intervention. Implement Sci. 2012;7.

70 Tsemberis S, Gulcur L, Nakae M. Housing First, consumer choice, and harm reduction for homeless individuals with a dual diagnosis. Am J Public Health. 2004;94:651-6.

71 Milby JB, Schumacher JE, Wallace D, Freedman MJ, Vuchinich RE. To house or not to house: the effects of providing housing to homeless substance abusers in treatment. Am J Public Health. 2005;95:1259-65.

72 Dickson-Gomez J, Convey M, Hilario H, Corbett AM, Weeks M. Unofficial policy: access to housing, housing information and social services among homeless drug users in Hartford, Connecticut. Subst Abuse Treat Prev Policy. 2007; 2:8

73 Raven MC, Doran KM, Kostrowski S, Gillespie CC, Elbel BD. An intervention to improve care and reduce costs for high-risk patients with frequent hospital admissions: a pilot study. BMC Health Serv Res. 2011;11:270.

74 Padgett DK, Stanhope V, Henwood BF, Stefancic A. Substance use outcomes among homeless clients with serious mental illness: comparing housing first with treatment first programs. Community Ment Health J. 2011;47:227-32.

75 Collins SE, Malone DK, Clifasefi SL, Ginzler JA, Garner MD, Burlingham B, et al. Project-based Housing First for chronically homeless individuals with alcohol problems: within-subjects analyses of 2-year alcohol trajectories. Am J Public Health. 2012;102:511-9.

76 Hwang SW, Stergiopoulos V, O'Campo P, Gozdzik A. Ending homelessness among people with mental illness: the At Home/Chez Soi randomized trial of a Housing First intervention in Toronto. BMC Public Health. 2012;12:787.

77 Tsemberis S, Kent D, Respress C. Housing stability and recovery among chronically homeless persons with co-occuring disorders in Washington, DC. Am J Public Health. 2012;102:13-6.

78 Stergiopoulos V, O'Campo P, Gozdzik A, Jeyaratnam J, Corneau S, Sarang A, et al. Moving from rhetoric to reality: adapting Housing First for homeless individuals with mental illness from ethno-racial groups. BMC Health Serv Res. 2012;12:345.

79 Collins SE, Malone DK, Clifasefi SL. Housing retention in single-site Housing First for chronically homeless individuals with severe alcohol problems. Am J Public Health. 2013;103:S269-74.

80 Srebnik D, Connor T, Sylla L. A pilot study of the impact of Housing Firstsupported housing for intensive users of medical hospitalization and sobering services. Am J Public Health. 2013;103:316-21. 
81 Farquhar SA, Ryder M, Henderlong D, Lowe RA, Amann T. Listening to consumer perspectives to inform addictions and housing-related practice and research. Glob J Community Psychol Pract. 2014;5:1.

82 Fleury M-J, Grenier G, Vallée C. Evaluation of the implementation of the Montreal At Home/Chez Soi project. BMC Health Serv Res. 2014;14:557.

83 Kertesz SG, Austin EL, Holmes SK, Pollio DE, Schumacher JE, White B, et al. Making Housing First happen: organizational leadership in VA's expansion of permanent supportive housing. J Gen Intern Med. 2014;29:835-44.

84 Mackelprang JL, Collins SE, Clifasefi SL. Housing First is associated with reduced use of emergency medical services. Prehospital Emerg Care Off J Natl Assoc EMS Physicians Natl Assoc State EMS Dir. 2014;18:476-82.

85 Aubry T, Nelson G, Tsemberis S. Housing First for people with severe mental illness who are homeless: a review of the research and findings from the At Home-Chez Soi demonstration project. Can J Psychiatry Rev Can Psychiatr. 2015;60:467-74.

86 Goering PN, Streiner DL. Putting Housing First: the evidence and impact. Can J Psychiatry Rev Can Psychiatr. 2015;60:465.

87 Henwood BF, Byrne T, Scriber B. Examining mortality among formerly homeless adults enrolled in Housing First: an observational study. BMC Public Health. 2015;15:1209.

88 Henwood BF, Stefancic A, Petering R, Schreiber S, Abrams C, Padgett DK Social relationships of dually diagnosed homeless adults following enrollment in Housing First or traditional treatment Services. J Soc Soc Work Res. 2015:6:385-406.

89 Kertesz SG, Austin EL, Holmes SK, Pollio DE, Lukas CV. Housing First and the risk of failure: a comment on Westermeyer and Lee (2013). J Nerv Ment Dis. 2015;203:559.

90 Ly A, Latimer E. Housing First impact on costs and associated cost offsets: a review of the literature. Can J Psychiatry. 2015;60:475-87.

91 Smelson DA, Chinman M, McCarthy S, Hannah G, Sawh L, Glickman M. A cluster randomized Hybrid Type III trial testing an implementation support strategy to facilitate the use of an evidence-based practice in VA homeless programs. Implement Sci. 2015;10:79.

92 Brown RT, Goodman L, Guzman D, Tieu L, Ponath C, Kushel MB. Pathways to homelessness among older homeless adults: results from the HOPE HOME study. PLoS One. 2016;11:e0155065.

93 Gabrielian S, Burns AV, Nanda N, Hellemann G, Kane V, Young AS. Factors associated with premature exits from supported housing. Psychiatr Serv Wash DC. 2016;67:86-93.

94 Kennedy DP, Hunter SB, Osilla KC, Maksabedian E, Golinelli D, Tucker JS. A computer-assisted motivational social network intervention to reduce alcohol, drug and HIV risk behaviors among Housing First residents. Addict Sci Clin Pract. 2016;11.

95 Killaspy H. Supported accommodation for people with mental health problems. World Psychiatry. 2016;15:74-5.

96 O'Campo P, Stergiopoulos V, Nir P, Levy M, Misir V, Chum A, et al. How did a Housing First intervention improve health and social outcomes among homeless adults with mental illness in Toronto? Two-year outcomes from a randomised trial. BMJ Open. 2016;6:e010581.

97 Stergiopoulos V, Gozdzik A, Misir V, Skosireva A, Sarang A, Connelly J, et al. The effectiveness of a Housing First adaptation for ethnic minority groups: findings of a pragmatic randomized controlled trial. BMC Public Health. 2016;16:1110.

\section{Submit your next manuscript to BioMed Central and we will help you at every step:}

- We accept pre-submission inquiries

- Our selector tool helps you to find the most relevant journal

- We provide round the clock customer support

- Convenient online submission

- Thorough peer review

- Inclusion in PubMed and all major indexing services

- Maximum visibility for your research

Submit your manuscript at www.biomedcentral.com/submit 